\title{
Le Cardinal Biayenda et le Congo-Brazzaville.
}

Colloque à l'Institut catholique de Paris, 14-15 février 2008. Paris, Karthala, 2012, 264 p., bibl.

Brice Arsène Mankou

\section{(2) OpenEdition}

12 Journals

Édition électronique

URL : http://journals.openedition.org/etudesafricaines/17855

DOI : 10.4000/etudesafricaines. 17855

ISSN : $1777-5353$

Éditeur

Éditions de l'EHESS

\section{Édition imprimée}

Date de publication : 3 octobre 2014

ISSN : 0008-0055

Référence électronique

Brice Arsène Mankou, "Le Cardinal Biayenda et le Congo-Brazzaville. », Cahiers d'études africaines [En ligne], 215 | 2014, mis en ligne le 02 octobre 2016, consulté le 23 septembre 2020. URL : http:// journals.openedition.org/etudesafricaines/17855; DOI : https://doi.org/10.4000/etudesafricaines. 17855

Ce document a été généré automatiquement le 23 septembre 2020.

(c) Cahiers d'Études africaines 


\section{Le Cardinal Biayenda et le Congo- Brazzaville.}

Colloque à l'Institut catholique de Paris, 14-15 février 2008. Paris, Karthala, 2012, 264 p., bibl.

Brice Arsène Mankou

\section{BAZENGUISSA-GANGA, Rémy, SOUNGA-BOUKONO, Gabriel \& TABARD, René (dir.). - Le Cardinal Biayenda et le Congo- Brazzaville. Colloque à l'Institut catholique de Paris, 14-15 février 2008. Paris, Karthala, 2012, 264 p., bibl.}

1 Qui a assassiné le cardinal Émile Biayenda et quelles sont les circonstances qui entourent le mystère de son assassinat? Telles sont les principales questions susceptibles d'intéresser les observateurs de l'histoire sociale du champ politique congolais qui, depuis le siècle dernier, est émaillée d'assassinats, d'intrigues politiques, de coups d'État et de logiques de guerre.

2 Le colloque, qui a réuni historiens, anthropologues, sociologues, politistes, théologiens, journalistes les 14 et 15 février 2008 à l'Institut catholique de Paris, avait pour objectif majeur d'aider à mieux comprendre le cardinal Émile Biayenda qui fut une figure historique du Congo-Brazzaville et de l'Église de ce pays d'Afrique centrale.

3 Il faut noter d'emblée que Rémy Bazenguissa-Ganga, qui s'intéresse au champ politique congolais, a déjà consacré une thèse de doctorat en sociologie à l'École des hautes études en sciences sociales en 1995 sur l'histoire sociale du champ politique de ce pays de 1946-1991'1 , sous la direction de Claudine Vidal. Les actes du colloque qu'il a codirigés à travers cet ouvrage, analysent le champs politique congolais en s'inspirant de la définition que Pierre Bourdieu² donne de la notion du «champ ", à savoir « un espace de relations objectives entre positions occupées par les acteurs ou des institutions, c'est-à-dire la structure qui détermine la forme de leurs actions et interactions et permet d'en rendre complètement raison ». 
4 Le cardinal Émile Biayenda était un de ces acteurs du champ politique congolais. Sociologue de formation, il a joué un rôle prépondérant dans l'histoire sociopolitique du Congo-Brazzaville. Mais pour comprendre cette histoire, il convient de s'interroger sur les grandes étapes de ce champ politique et social congolais. Pour en saisir les étapes, l'historienne Catherine Coquery-Vidrovitch décrit cette histoire qui, d'après elle, remonte à février 1959, année de la première émeute brazzavilloise qui opposa deux ethnies, les Lari $^{3}$ et les Mbochi ${ }^{4}$. Ce fut, selon elle, "l'origine de la première manifestation d'ethnicité tribalisme pendant une semaine, dans le quartier Bakongo ${ }^{5}$ " (p. 17).

5 Aujourd'hui plus qu'hier, l'ethnicité et le tribalisme continuent de gangrener la démocratie congolaise, dans la mesure où les politiques, tous bords confondus, se servent de ces entités socioculturelles pour accéder ou conserver le pouvoir. C'est ce que Florence Bernault ${ }^{6}$ qualifie, à juste titre, de «tribalisme politique». Un tribalisme qui est considéré, selon moi, comme une "source de guerres civiles, de violence politique et ethnique en Afrique $»^{7}$.

6 Cet ouvrage apparaît donc comme un traité d'histoire sur la violence politique au Congo-Brazzaville dont la conséquence a été l'assassinat d'un homme d'Église le 22 mars 1977, dans ce pays. Un pays qui, selon Abel Kouvouama ${ }^{8}$, «fait partie des sociétés africaines subsahariennes qui articulent des totalités sociopolitiques enchevêtrées dont le dénominateur commun est l'avant et l'après "situation coloniales" (selon la formule de Georges Balandier).

7 Pour mieux comprendre le contexte politique et social de l'histoire du CongoBrazzaville, il est intéressant de relire l'ouvrage de Georges Balandier Sociologie des Brazzavilles noires. Cet ouvrage qui, selon Rémy Bazenguissa-Ganga, « est une première étude effectuée sur la capitale, née de la colonisation d'un pays africain, prit le parti de la considérer comme une ville noire, c'est-à-dire ayant des dynamiques propres et complexes, et non seulement comme la réalisation servile d'une ville blanche en Afrique Équatoriale $»^{9}$.

8 Le climat des Brazzavilles noires qui fait suite aux assassinats politiques, aux désordres sociaux dont les facteurs explicatifs selon l'auteur sont à rechercher du côté « de la théologie politique et du marxisme-léninisme congolais» (p.51). Selon lui, «l'assassinat du Cardinal Émile Biayenda, en mars 1977, intervient en l'espace de quelques jours, avec l'élimination de deux autres personnalités congolaises: le président Marien Ngouabi et l'ancien président Massamba-Débat » (ibid.). Au CongoBrazzaville, le marxisme-léninisme s'accompagnait de slogans porteurs de sémantique guerrière $^{10}$, comme "le pouvoir est au bout du fusil », "seule la lutte libère », «le pouvoir ne se donne pas, il s'arrache » ou «Production-discipline-fusil » pour l'Union de la jeunesse socialiste congolaise, unique mouvement de jeunes sous le parti unique.

9 Ce contexte de tensions prédisposait déjà le Congo-Brazzaville à ce que Joseph Tonda ${ }^{11}$ appelle « la division de l'espace national en un Nord Bangala ou Mbochi d'une part, et en un Sud Kongo d'autre part ». Cette production de l'ethnicité que nous retrouvons dans les travaux de J.-L. Amselle et E. M'Bokolo ${ }^{12}$ s'inspire des recherches de Georges Balandier qui, selon Rémy Bazenguissa-Ganga, "montrait déjà comment dans la multitude des groupes sociaux précoloniaux, les Kongo et les Mbochi prirent l'ascendant sur les autres et surtout sur les Téké, les véritables autochtones de Brazzaville $»^{13}$. 
Face aux velléités ethniques et tribales qui faisaient suite à l'assassinat du président Marien Ngouabi, le 18 mars 1977, le cardinal Émile Biayenda, peu avant sa mort, livrait un message dont la portée est encore actuelle pour le Congo-Brazzaville : «À tous nos frères croyants $\mathrm{du}$ Nord, $\mathrm{du}$ Centre et $\mathrm{du}$ Sud, en souvenir du président Marien Ngouabi, nous demandons beaucoup de calme, de fraternité et de confiance en Dieu, Père de toutes les races et de toutes les tribus, afin qu'aucun geste déraisonnable ne puisse compromettre un climat de paix que nous souhaitons tous $»^{14}$.

11 La Conférence nationale souveraine de 1991 n'a pu désigner l'assassin du cardinal ; ce colloque et cet ouvrage n'y sont pas davantage parvenus, ce qui peut représenter une frustration pour le lecteur et pour l'Église, d'autant plus que le Vatican a ouvert une enquête pour sa canonisation.

\section{NOTES}

1. R. BAZENGUISSA-GANGA, Histoire sociale du champ politique congolais, 1946-1991, Thèse de doctorat, Paris, EHESS, 1995.

2. P. BOURDIEU, Les règles de l'art: Genèse et structure du champ littéraire, Paris, Éditions du Seuil, 1992.

3. Dans ce conflit de 1959, les Lari constituent l'ethnie des ressortissants de la région du Pool dans le sud du Congo-Brazzaville.

4. Les Mbochi sont les membres de l'ethnie des ressortissants de la cuvette centrale, notamment autour des villages comme Boundji, Oyo et Ollombo.

5. Le quartier Bakongo est un quartier célèbre de Brazzaville situé au sud de la capitale et qui est considéré comme le siège des « sapeurs ".

6. F. BERNAULT, Démocraties ambiguës en Afrique Centrale, Congo-Brazzaville, Gabon, 1940-1965, Paris, Karthala, 1996, p. 284.

7. B. A. MANKOU, «Le tribalisme, source de violence politique et ethnique en Afrique ", Le Portique, 2007, pp. 1-7.

8. A. кouvouama, "Les pratiques de terrain en situation de tensions sociales et de guerre civile au Congo-Brazzaville", Sociologies, oct. 2011, <http:// www.sociologies.revue.org/3724>.

9. R. BAZENGUISSA-GANGA, Histoire sociale du champ politique congolais, 1946-1991, op. cit., p. 1.

10. Tous ces slogans guerriers sous le monopartisme traduisaient déjà l'état d'esprit des politiques et des mouvements de jeunesse formatés dans la lutte de conservation du pouvoir.

11. J. TONDA, «La guerre dans le "Camp Nord" au Congo-Brazzaville: ethnicité et ethos de la consommation/consumation ", Politique Africaine, 72, 1998, pp. 51-67.

12. J.-L. AMSELLE \& E. м'вокоцо (dir.), Au cœur de l'ethnie. Ethnie, tribalisme et État en Afrique, Paris, La Découverte, 1985. 
13. R. BAZENGUISSA-GANGA, op. cit., p. 4.

14. Message du cardinal Émile Biayenda, Archevêque de Brazzaville, peu avant son assassinat le 18 mars 1977. 